\title{
Social Innovation Capital
}

\author{
By Mark W. McElroy \\ President, Macroinnovation Associates, LLC
}

\begin{abstract}
Current conceptions of how to measure and manage intellectual capital (IC) suffer from a failure to take 'social capital' rigorously into account. This is a shortcoming of current thinking in the IC arena. Of particular concern is the absence of 'social innovation capital' (SIC) from the scope of leading IC schemes. Social innovation capital, the collective capacity of a firm to innovate, is arguably the most valuable form of IC because it underlies a firm's fundamental capacity to learn, innovate, and adapt. Using one leading IC scheme as a basis for analysis (Skandia's), the absence of social capital, and SIC in particular, is highlighted, along with a description of what Skandia's taxonomy would look like if it were to take social capital fully into account. Finally, recommendations are offered on how managers can build and manage SIC, thereby enhancing their organizations' capacities to learn, innovate, and adapt in the marketplace.
\end{abstract}

\section{Part I - Redefining Intellectual Capital}

With companies around the world now routinely trading at levels far beyond their book values, senior managers, accountants, and other business executives have been increasingly focusing on the new field of intellectual capital. Intangible assets, or 'goodwill,' as it is sometimes referred to, have always played a role to some degree or other in corporate valuations, but the proportion of such intangibles in today's 'market caps' has reached unprecedented levels. The aggregate price of the Dow Jones 30 Industrials in 1997, for example, exceeded the combined book values of the member companies by a factor of three-to-one. For many companies today, this ratio is much higher. 
Not surprisingly, managers interested in getting their arms around intellectual capital are searching for ways to describe, measure, and manage their intangible assets with a particular emphasis on capturing their favorable effects on the bottom line and on shareholder values. Chief among these intrepid pioneers has been Leif Edvinsson, former Corporate Director of Intellectual Capital at Skandia AFS, and current Visiting Professor of IC/Knowledge Economics at Lund University's School of Economics and Management in Sweden, who along with Michael Malone, co-authored the influential text entitled, Intellectual Capital (Edvinsson and Malone, 1997). In their fine treatise of the subject, Edvinsson's experiences at Skandia in developing an intellectual capital (IC) management scheme are meticulously described. Of particular interest is the manner in which Skandia chose to map its IC territory (see Figure 1).

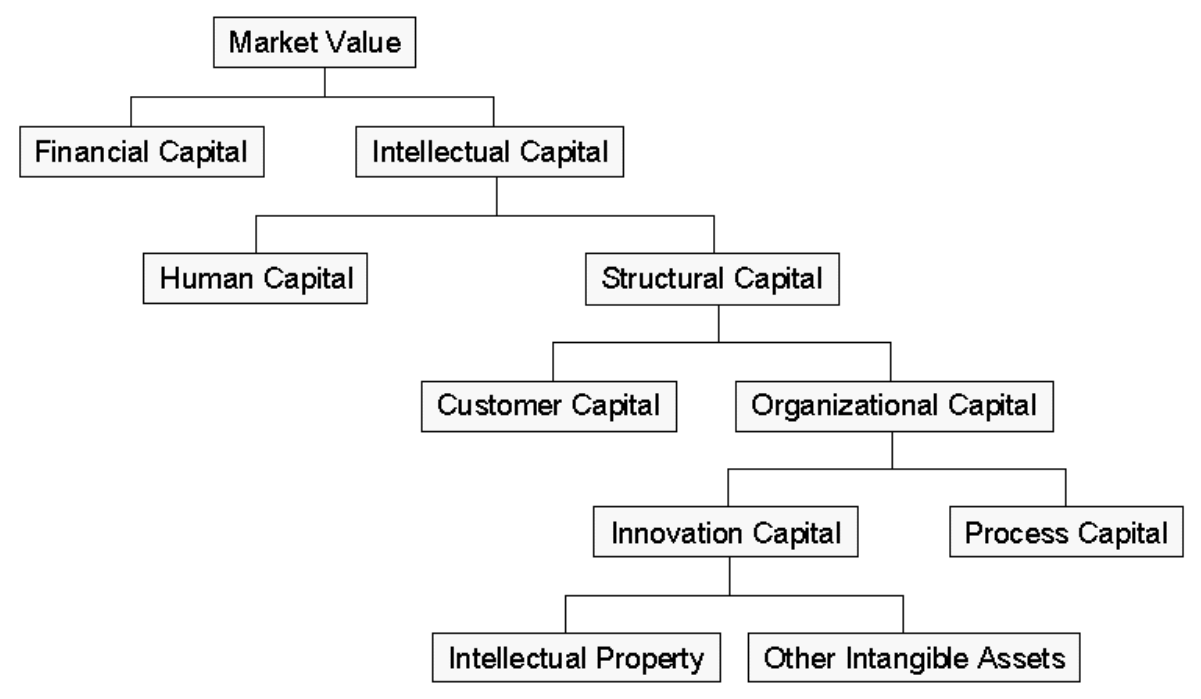

Figure 1 - Leif Edvinsson's IC model for Skandia SFC

In Edvinsson's scheme, IC is composed of two major elements: human capital and structural capital. According to Edvinsson's view of IC (shown in Figure 1), human 
capital refers to the value of knowledge, skills and experiences held by individual employees in a firm; structural capital consists of what Edvinsson and Malone refer to as the "embodiment, empowerment, and supportive infrastructure of human capital." As such, it includes all the things that support human capital in a firm, but which are left behind when employees go home at the end of the day. And last, customer capital, is the value of customer relationships.

Despite the groundbreaking advances made by Edvinsson and his team at Skandia AFS since they started in the early ' $90 \mathrm{~s}$, their model fails to take into account a fourth major component of intangible value now commonly recognized on other fronts: social capital. Unlike the other forms of IC, social capital points to the value of relationships between people in firms, and between firms and other firms. Trust, reciprocity, shared values, networking, and norms are all things that, according to social capital theory, add value in a firm, or between firms, by speeding the transfer of information and the development of new knowledge. In a sense, what Edvinsson refers to as customer capital is merely a form of social capital by another name, albeit only between a company and its customers. But social capital can take other forms, the combination of which unquestionably adds value to a firm; is intangible; and clearly warrants a prominent place in the taxonomy of IC.

Turning to the realm of social capital theory, then, we find two major schools of thought (Lesser, 2000). The first is the so-called 'egocentric' perspective, in which social capital is seen as the value of an individual's relationships with other individuals in helping to get things done in a firm. The other is the 'sociocentric' model in which social capital is still held by individuals, but has more to do with the added value of their position in the structure of a firm than with their interpersonal relationships, per se.

But there is arguably another form of social capital (one of many, I'm sure), that is of particular relevance to this discussion. I call it 'social innovation capital' (SIC). Here, I use the term in such a way that the root concept is 'innovation capital,' which is modified by the adjective 'social.' In other words, the concept refers to innovation capital of a 
social kind (held by, and in the form of, a collective), as opposed to, say, innovation capital of an individual kind (held only by individuals). Social innovation capital, then, refers to the collective manner in which whole social systems (i.e., firms) organize themselves around - and carry out - the production and integration of new knowledge.

By recognizing such social innovation capital, managers can not only measure and value their firms' capacity to innovate, but can also enhance their performance and output as well (i.e., their capacity to innovate and their innovations). In other words, by managing social innovation capital, managers can improve the rate and quality of innovation in their firms, as well as their competitive stance in the marketplace. Indeed, this is the value proposition of managing social innovation capital, and is also the basis for advocating its inclusion in the formal typology of intellectual capital. Recognizing not only a firm's intellectual output, but its capacity to produce such output as a valuable intangible in its own right, is wholly appropriate in a world where survival has everything to do with a firm's capacity to sustainably out-learn and out-innovate its competitors.

While it is true that Edvinsson's scheme does already have a place for the notion of 'innovation capital' (see Figure 1), he positions it as a subset of structural capital and defines it mostly in terms of intellectual properties (i.e., patents, trademarks, and copyrights). In so doing, Edvinsson places his emphasis on innovations, as in outputs or work products, but not on innovation, as in process. Elsewhere in Skandia's model we see Edvinsson's reference to process capital, which at first might be interpreted as inclusive of innovation processes, but here again he defines his category in terms that have little to do with innovation, per se. Instead, Edvinsson's notion of process capital focuses mostly on operations or business processes, not the meta-operations or knowledge processes of interest to us in the context of innovation. In sum, there is no place for the kind of social innovation capital I speak of anywhere in Edvinsson's model, much less a place for social capital of any other kind.

So, given the sunstantial absence of social capital in Edvinsson's model, I propose a major modification to it (and to all IC models, in general) which includes the addition of 
both social capital and the underlying notion of social innovation capital (see Figure 2). In this modified IC model, I also fix what I believe is another shortcoming in Edvinsson's treatment of customer capital by placing it in context with other forms of 'relationship capital,' a term that Tom Stewart uses in his book, also titled Intellectual Capital (Stewart, 1997). I accomplish this by repositioning customer capital as a subcategory under the heading of social capital where it belongs.

Finally, while there are many references in the literature to notions of 'networks' as expressions or forms of social capital, the same literature fails to differentiate between one type of network and another in terms that might ascribe different levels of value, or purpose, to different kinds of networks. Here, I propose the notion of characteristic patterns of networks, or archetypes, and suggest that one such pattern which has its own tell-tale identity is the kind that self-organizes around the production and integration of knowledge. This is what I mean by social innovation capital: a particular archetypical social pattern which has as its aim the production, diffusion and application of new knowledge by, and for, an organization. Indeed, all firms produce new knowledge according to some such pattern(s), and so their SIC can, and should, be described, accordingly.

Co-authors Janine Nahapiet and Sumantra Ghoshal point out in their very fine paper, Social Capital, Intellectual Capital, and the Organizational Advantage (Nahapiet and Ghoshal, 1996), “...we use the concept of the structural dimension of social capital to refer to the overall pattern of connections between actors - that is, who you reach and how you reach them." [emphasis added] But while the same authors fail to name those patterns, I offer the following description of SIC: a collection of independent learners and communities of practice who collaborate with one another in self-organizing ways to develop and integrate shared knowledge. 'Communities of practice' and other types of communities are the wellsprings of knowledge in business and it is their characteristic pattern of formation and behavior that largely comprises what I refer to as social innovation capital. This pattern therefore includes not only the characteristic, knowledge-making behavior of communities, but also the embryology through which 
they form (i.e., the co-attraction of independent learners). Indeed, the relative health of an organization's community of communities, as well as the quality of its breeding grounds, are two important measures of value in a firm's SIC.

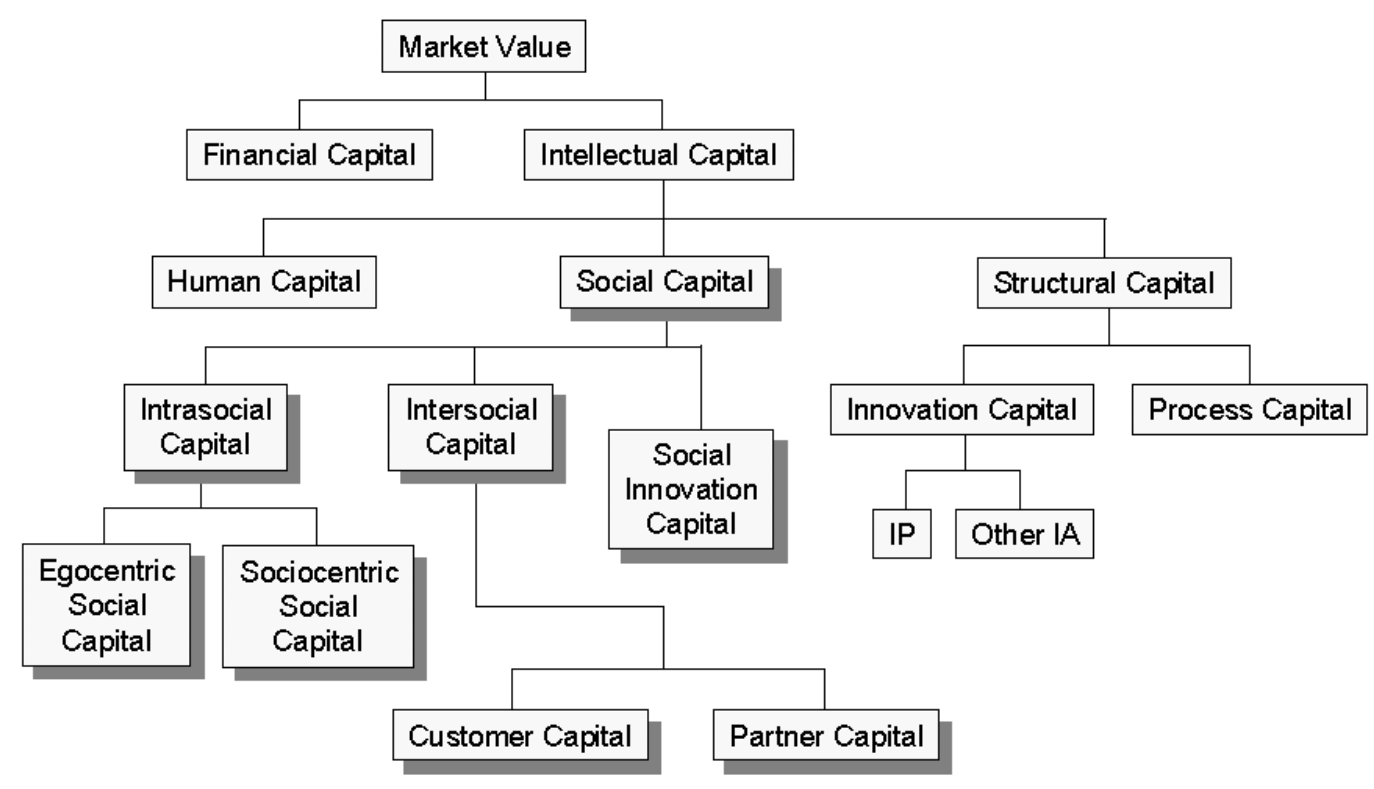

Figure 2 - McElroy's modified IC map with social capital thread added and customer capital repositioned within its bounds

The failure of social capital theorists to refer not only to 'networks of people' as social capital, but to specific patterns of networks as such, is a bit like referring to the weather as 'nothing but a mix of meteorological activity.' Failing to differentiate between tornadoes, hurricanes, tsunamis, and heat waves leaves much to be desired. The same is true in human social systems. The manner in which people self-organize around the production and integration of new knowledge in organizations has a characteristic pattern to it like no other. It should be recognized, named, and managed as such. Indeed, the healthy presence of this pattern is of great value to a firm, and so I choose to acknowledge it as social innovation capital. 
To successfully propagate these patterns of innovation - and thereby trigger improvements in the rate and quality of IC production - managers of SIC must focus on enabling independent, self-directed learning for individuals; community formation and support for groups; and the consideration of community-made knowledge in the formal knowledge processing and integration affairs of their firms. By treating learning and innovation as social processes, not administrative ones, and by focusing on ensuring the health and well-being of related patterns of behavior, managers can markedly improve the value of their firms' IC and achieve sustainable innovation in the process.

\section{Part II - Practice Implications}

Before continuing, I should take care to point out that the foregoing discussion of how best to characterize intellectual capital is based on only one such scheme: Leif Edvinsson's Navigator model as developed by him and his team at Skandia SFS. There are certainly others, as well. But since it was not my intent in writing this paper to perform a critique of all such methods - rather, only to highlight the omission of social capital in one of them for illustrative purposes - I chose the Skandia model because of its hierarchical composition, and its apparently high standing in IC circles. That said, however, I would levy the same criticism to all other expressions of intellectual capital, which so far as I know each suffer from the same deficiency: the omission of social capital in any sort of comprehensive form.

In their failure to embrace social capital, the Skandia model and others necessarily fail to address innovation, per se, since innovation is without a doubt a social process. Knowledge production in human social systems has long been recognized as a function of collaboration between individuals in communities of interest, practice, etc., as exemplified in Thomas S. Kuhn's study of the history of science in his well known book, The Structure of Scientific Revolutions (Kuhn, 1962). For those who may still harbor doubts about whether or not innovation is a social process - that is, as opposed to an administrative one - I suggest a quick revisit to Kuhn's fascinating history of paradigm shifts, in which the social nature of knowledge production is made abundantly clear. 
Despite disagreements on the validity of the specific dynamics that Kuhn claimed were responsible for major innovations, few would disagree with his characterization of innovation is a social phenomenon, not an administrative one.

From the perspective of intellectual capital management, the significance of seeing innovation as a social process is at least twofold. First, it tells us that one very important form of IC - if not the most important one - is the social capacity to innovate in a firm. Moreover, not all such capacities are equal across firms. Here, the importance of social capital, in general, really shines through, since trust, reciprocity, relationships, and norms all arguably enhance a firm's collective capacity to collaborate around the production of new knowledge. A firm that scores higher in the presence and quality of these attributes, and the strength of the networks in which they are found, can be seen as having a higher economic value than its competitors whose corresponding measures are lower.

Next, the view of innovation as a social process also helps us understand that in a very real sense, innovation is an unmanaged process. Indeed, it is a self-organizing one. This explains the very strong connections now seen between innovation and complexity theory, which is nothing if not the study of self-organization in dynamic systems. The management implications here are profound. While there's certainly nothing wrong with current attempts to manage innovation in the administrative sense (i.e., managing $R \& D$ functions, etc.), tapping a firm's natural ability to self-organize around innovation on an enterprise-wide basis should also be seen as a source of competitive advantage. Why not engage the whole firm in the learning and innovation process? Why stop at the borders of the R\&D function, or with the ranks of senior management?

I will now lay claim to the assertion that social innovation capital (SIC) is, in fact, the most valuable form of IC. I say this because it is the only form of IC that has as its purpose the creation of all other forms of IC, including itself. Social innovation capital is therefore a necessary precondition (or antecedent) to the production of all forms of IC, including valuable intellectual property (IP), such as patents, trademarks, and copyrights. In the absence of SIC - or in the presence of weak SIC - the effects of even the most 
valuable IP are merely ephemeral. Like all knowledge, the value of discrete IP eventually expires, or at least diminishes over time. Longevity in business therefore depends upon having a continuous stream of new innovations, new patents, new ideas, new insights, and new bases of competitive advantage. Only social innovation capital can deliver that kind of value because innovation is, after all, a social process.

I should now differentiate between the remaining issues of (1) how to establish strong social innovation capital, and (2) how to value SIC and its output. With this distinction in mind, I will only be dealing with the former issue for the remainder of this paper, since the latter one calls for its own, logically subsequent treatment. Let us first discuss the composition of social innovation capital, what its drivers are, and how to manage it.

Over the past three years, I and several other members of the Knowledge Management Consortium International, or KMCI (vww.kmci.org. have been working to develop and elaboration of the claim that 'innovation is a social process, not an administrative one,' in a way that would give managers a means of managing the flow and quality of knowledge production and use. Truisms are informative, but it takes more than provocative slogans to make a difference in business. If innovation is truly a social process, we argued, it probably takes the form of regular patterns of behavior in human social systems that can be discovered and described as such. Out of this effort came the depiction of organizational innovation shown in Figure 3. 


\section{The KMCl's Knowledge Life Cycle}

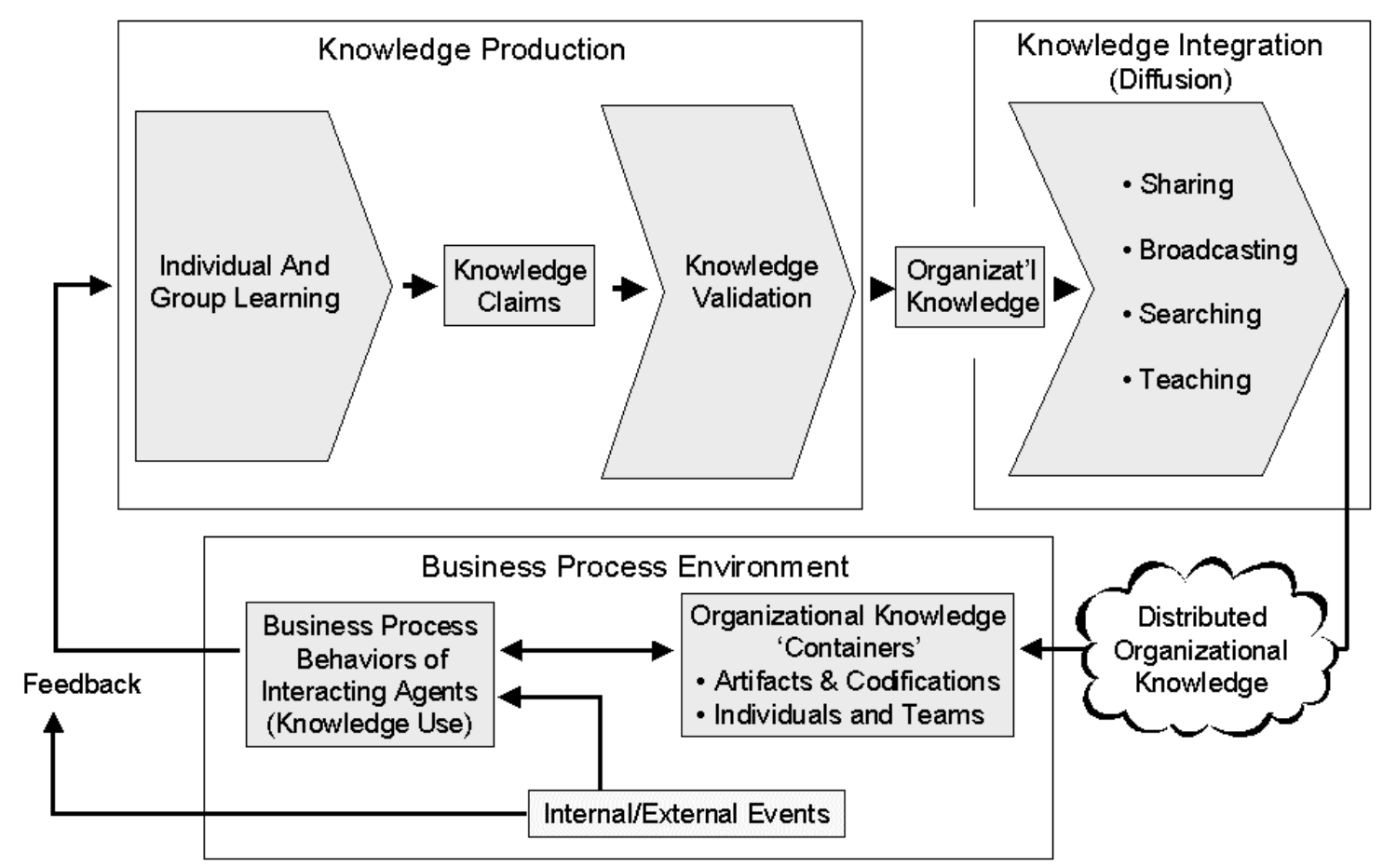

Figure 3 - The KMCI Knowledge Life Cycle

Those of us responsible for the production of this model have been careful to point out that it is more a 'framework' than a theory, since it is only meant to describe the broad pattern of knowledge production and integration in a firm (i.e., innovation) without necessarily attempting to put forth specific theories as to how, for example, groups or communities 'validate' knowledge. The model simply suggests, instead, that validation of some kind happens as a precursor to the adoption and integration of new knowledge at an organizational level. Each element of this framework is therefore merely a placeholder for one or more theories on how the related functions or behaviors occur. The relationships between them, however, and the overall pattern that they form when placed in context with one another is the self-organizing social phenomenon that is the hallmark of the KMCI view. The pattern of processes depicted in the KMCI model is the pattern of social innovation capital of interest to us here. 
In an effort to isolate the drivers of knowledge production and integration in a firm, I have found it useful to portray the life cycle in a slightly different, and simpler, way (see Figure 4). Here, the pattern of the KMCI's life cycle is highlighted around the edge of a simple cycle in a sequential fashion. These are the key dynamics, I argue, in the self-organized expression of innovation in human social systems. In other words, these are the fundamental steps that must be allowed to occur in order for enterprise-wide innovation to unfold to its full potential - its critical path, if you like.

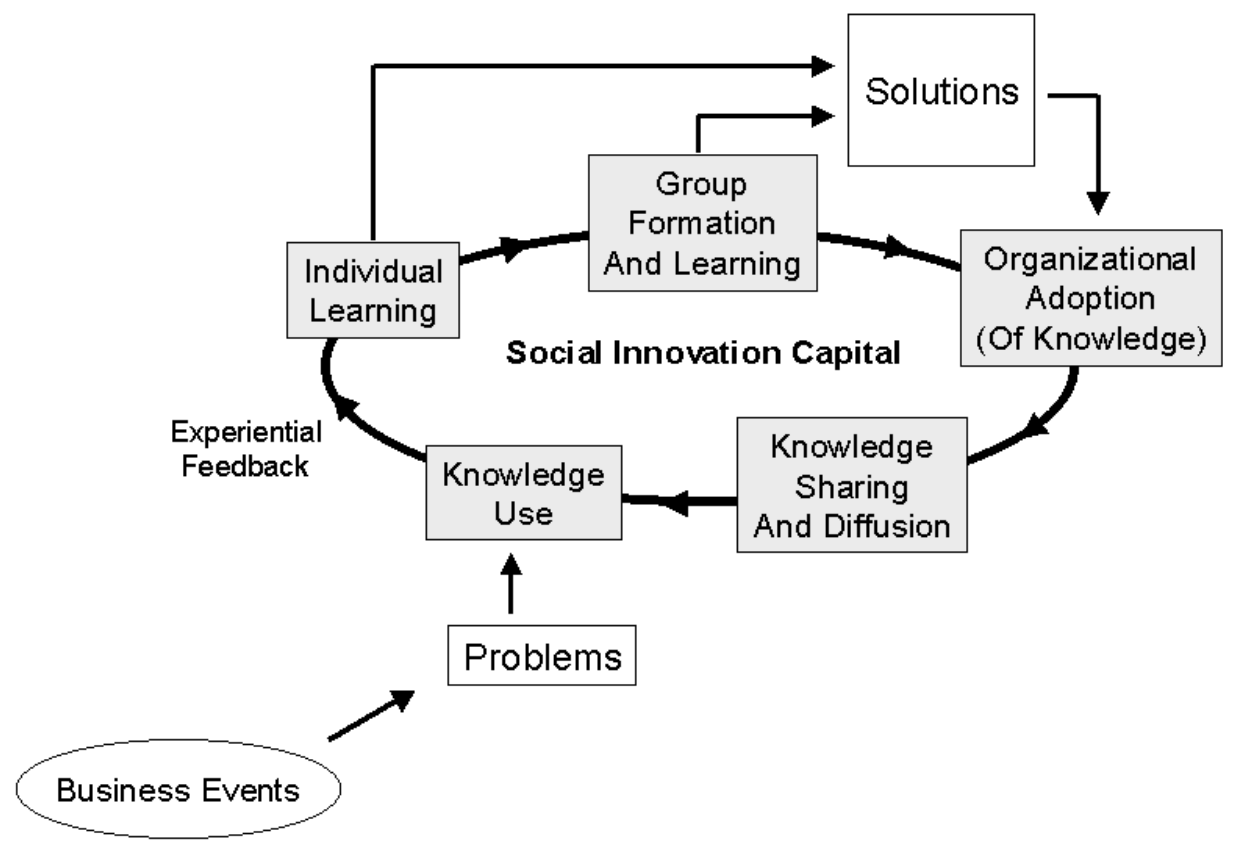

Figure 4 - The self-organizing pattern of social innovation capital

Any organization, left to its own devices, will eventually start to display the pattern shown in Figure 4. This speaks to the tendency of human social systems to self-organize around the production, diffusion, and use of new knowledge. The literature in anthropology, sociology, political science, social psychology, and the life sciences generally points to the role that such cycles play in group learning and adaptation as the raison d'etre behind them. Indeed, there's no shortage of explanations as to how these 
cycles account for learning, innovation, and adaptive behavior in human social systems. The more important point for us right now is that these cycles invariably unfold under their own steam; they are self-propelled. Human social systems want to express their innovation affairs in these ways, and always will, even - and especially - in the complete absence of management of any kind. The self-organized expression of these patterns is ineluctable.

Fortunately for business, the full expression of these self-organized patterns of innovation is a good thing because they lead to the production of new knowledge that has financial value implications. In some cases, the knowledge produced by healthy social innovation capital has direct value, as in the case of intellectual property, such as patents, trademarks, and copyrights. In other cases, the value is indirect to the bottom line, such as well-crafted strategies, efficient organizational models, and flexible manufacturing schemes. What every business manager should therefore want is well-running social innovation capital that continues to supply its host organization with one new innovation after another.

But since social innovation capital of the sort I have described is self-organizing in its ontogeny, in what sense would a manager manage such a thing? The answer? By getting the hell out of its way! That's the flip response, for effect; now here's the practical one.

One of the key lessons from complexity theory is that visions of managing selforganizing systems are illusory, especially when it comes to 'managing' collective behaviors in dynamic systems. According to this insight, knowledge-making in human social systems is arguably independent of outside intervention despite managers' best intentions, so the best we can ever hope to achieve in encouraging innovation is to manage the surrounding conditions - the innovation climate, if you will.

Within the innovation climate of a firm, there are four dimensions, in particular, that have a direct impact on the degree to which self-organized learning and knowledge production can occur. Depending on how well these dimensions are aligned, or synchronized, with 
the tendency of people to behave in the ways described in Figure 4, the overall level and quality of innovation in a firm will vary. Management policies in all four areas can therefore be fashioned in such a way that they support, strengthen, and reinforce knowledge making and sharing in human social systems.

The four areas of relevant innovation policies are as follows:

1. Learning - Management policies that determine the degree of freedom individuals in a firm have to pursue learning agendas of their own choosing and direction. Also includes policies related to the degree of freedom groups or communities have to (a) self-organize and form around areas of common interest and practice, and (b) to carry out their group-level knowledge processing affairs.

2. Knowledge Processing - Policies that determine the manner in which firms create, share, and apply new knowledge, as well as the extent to which, and how, they share the benefits of their knowledge (title, economic rewards, or otherwise) with their employees.

3. Connectedness - Policies which determine the extent to which workers in a firm can, and do, connect to one another with ease, either through technology infrastructures or social networks. The nature and frequency of interactions between co-workers is of interest to us here.

4. Ethodiversity - Management policies that determine the diversity of ethos(es) a firm. Usually takes the form of HR recruiting and retention policies. The 'ethography' of an organization is a measure of its 'ethodiversity,' and determines the diversity of values and worldviews that a firm will have at its disposal as it attempts to learn, innovate, and adapt.

What I am advocating here is the active management not of innovation, per se, but of the policies that comprise the relevant conditions in which innovation occurs. One can no more manage self-organizing processes than a gardener can order her plants to grow. But given the predisposition of human social systems to innovate under their own steam, it makes all the sense in the world to manage the conditions in which such behaviors 
independently unfold, so as to support, strengthen and reinforce their progression (see Figure 5). Like gardeners, innovation managers should focus first on understanding how the system of interest to them behaves, and should then concentrate on adopting policies that will ensure a supportive environment. This is the only sensible way to 'manage' self-organizing systems. In truth, it is their surroundings that are managed, not the systems themselves. After all, gardeners don't 'grow plants,' they manage soil and environmental conditions. The plants grow themselves.

The methodology described above is called the "policy synchronization method" (PSM). Unlike other innovation management schemes predicated on the view that innovation is a manageable, administrative process, the PSM method rejects that premise, and in the process offers a more effective prescription for sustainable innovation. This is because it is the only innovation management method extant that takes a deferential approach to the presence of self-organized innovation in a firm. Rather than compete with these forces or, worse yet, ignore them, the PSM method acknowledges them, and focuses explicitly on their protection and support. Innovation management schemes that fail to take this first critical and deferential step are ultimately unsustainable because they run counter to the predispositional tendency of human social systems to innovate in their own endemic ways. Over time, the friction between management policy and social tendencies, in such cases, can actually undermine innovation. 


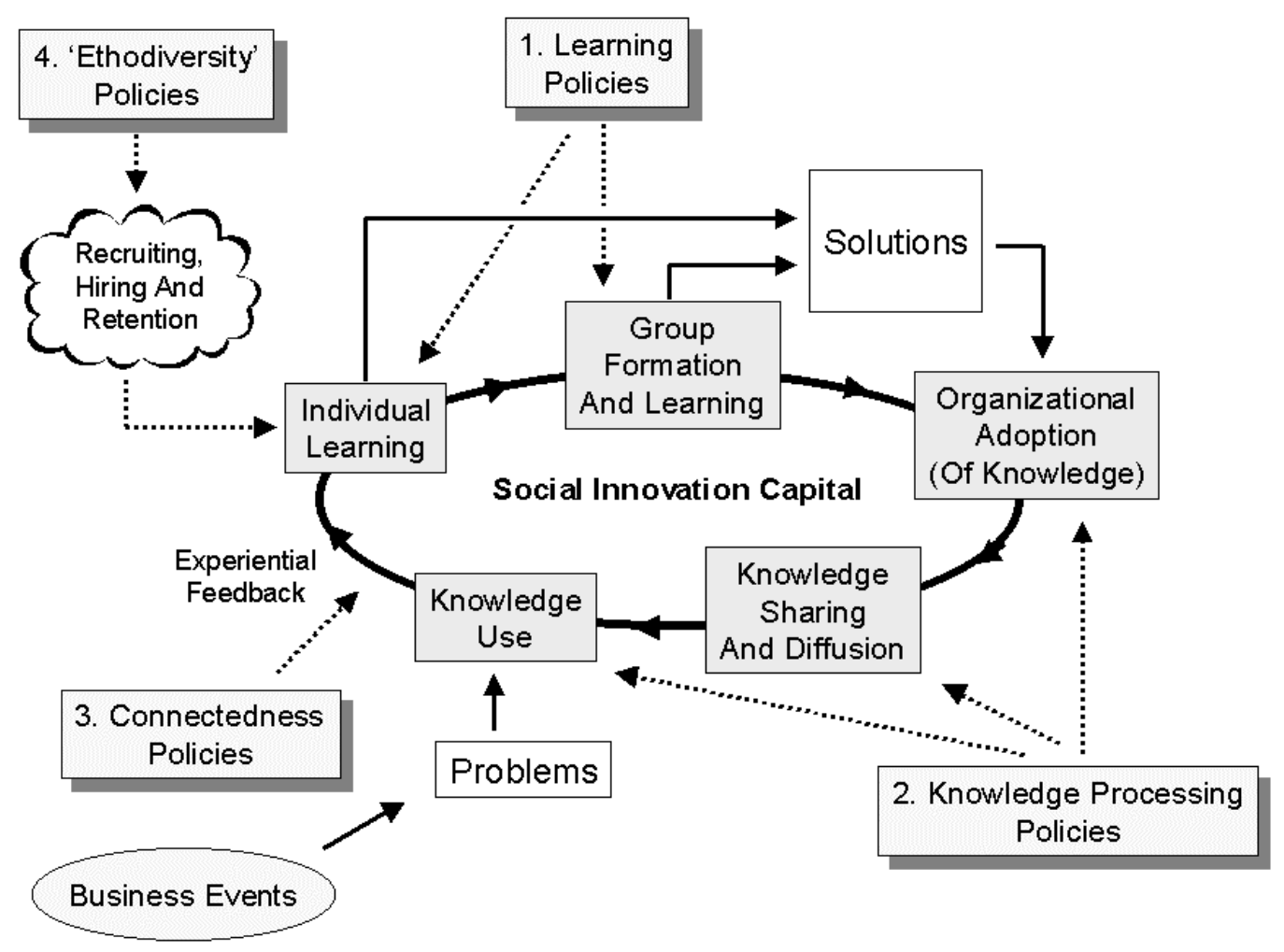

Figure 5 - The Policy Synchronization Method Applied to SIC

Whereas in the practice of conventional management, policies are used to determine social behavior, in the case of the PSM method, the reverse is true - behavior drives policy. By adopting policies that support, strengthen, and reinforce endemic patterns of innovation, managers can have direct impact on the quality of a firm's social innovation capital, and thereby ensure the conditions required for sustainable innovation and high market value.

$$
* \quad * \quad * \quad *
$$

\section{$\underline{\text { References }}$}

1. Edvinsson, L., and Malone, M. Intellectual Capital. New York: HarperBusiness, 1997.

2. Kuhn, T. Structure of Scientific Revolutions. Chicago: University of Chicago Press, 1962. 
3. Lesser, E. Knowledge and Social Capital. Boston: Butterworth Heinemann, 2000.

4. Nahapiet, J., and Ghoshal, S. "Social Capital, Intellectual Capital, and the

Organizational Advantage.” Academy of Management Review Vol. 23:2, pp. 242-266 (1996).

5. Stewart, T. Intellectual Capital. New York: Currency Doubleday, 1999.

\begin{abstract}
About The Author
Mark W. McElroy is the founder and president of Macroinnovation Associates, LLC, an innovation methodology shop located in Windsor, Vermont. Macroinnovation Associates is the developer of the 'policy synchronization method,' a patent-pending technique for improving business innovation based on principles taken from organizational learning and complexity theory.
\end{abstract}

Mark can be reached by e-mail at nmcelroy@vermontel.net. 